\title{
ALTERNATIVE FUELS AND CHEMICALS FROM SYNTHESIS GAS
}

\section{FINAL}

Technical Progress Report No. 31

For the Period 1 April - 30 June 2002

\author{
Contractor \\ AIR PRODUCTS AND CHEMICALS, INC. \\ 7201 Hamilton Boulevard \\ Allentown, PA 18195-1501 \\ Prepared for the United States Department of Energy \\ Under Contract No. DE-FC22-95PC93052 \\ Contract Period 29 December 1994 - 31 July 2002
}

NOTE: AIR PRODUCTS DOES NOT CONSIDER ANYTHING IN THIS REPORT TO BE CONFIDENTIAL OR PATENTABLE. 


\section{DISCLAIMER}

This work was prepared as an account of work sponsored by the United States Government. Neither the United States nor the United States Department of Energy, nor any of their employees, makes any warranty, express or implied, or assumes any legal liability for the accuracy, completeness, or usefulness of any information, apparatus, product, or process disclosed, or represents that its use would not infringe privately owned rights. Reference herein to any specific commercial product, process, or service by trade name, mark, manufacturer, or otherwise, does not necessarily constitute or imply its endorsement, recommendation, or favoring by the United States Government or any agency thereof. The views and opinions of authors expressed herein do not necessarily state or reflect those of the United States Government or any agency thereof. 


\title{
Alternative Fuels and Chemicals from Synthesis Gas
}

\author{
Technical Progress Report
}

1 April - 30 June 2002

\section{Contract Objectives}

The overall objectives of this program are to investigate potential technologies for the conversion of synthesis gas to oxygenated and hydrocarbon fuels and industrial chemicals, and to demonstrate the most promising technologies at DOE's LaPorte, Texas, Slurry Phase Alternative Fuels Development Unit (AFDU). The program will involve a continuation of the work performed under the Alternative Fuels from Coal-Derived Synthesis Gas Program and will draw upon information and technologies generated in parallel current and future DOE-funded contracts.

\section{RESULTS AND DISCUSSION}

\section{TASK 1: ENGINEERING AND MODIFICATIONS - no activity this quarter}

\section{TASK 2: AFDU SHAKEDOWN, OPERATIONS, DEACTIVATION AND DISPOSAL - no activity this quarter}

\section{TASK 3: RESEARCH AND DEVELOPMENT}

\section{Qualification of Alternative Methanol Catalysts}

- Continuing our efforts to qualify alternative methanol catalysts for LP commercial use, a commercial methanol catalyst from China was tested under our LPMEOH ${ }^{\mathrm{TM}}$ baseline conditions. The catalyst stability is similar to our standard methanol catalyst, reaching the baseline aging rate after 150 hours on stream. Its initial activity is $10 \%$ lower than that of the standard catalyst. Analysis showed that the pore volume of this commercial catalyst we tested is greater than that of our standard methanol catalyst. This translates into possibly lower allowable catalyst loading compared to our standard catalyst.

- A third commercial methanol catalyst was tested in the lab reactor under LPMEOH ${ }^{\mathrm{TM}}$ conditions. Its behavior was similar to that of the first commercial methanol catalyst we tested. The initial activity of this catalyst was $22 \%$ lower than our standard methanol catalyst. It experienced greater-than-baseline deactivation for the first 300 hours on stream before it 
settled to the baseline aging. However, some stepwise changes suggest that lab reactor artifacts might have contributed to the initial, greater-than-baseline catalyst aging.

- A fourth commercial methanol catalyst sample from a major methanol catalyst manufacturer has been received.

\section{LPMEOH ${ }^{T M}$ Life Study}

Efforts were continued to understand and mitigate lab reactor artifacts, and improve the precision and reliability of catalyst-aging experiments.

- In April we added small glass beads to the reactor, hoping that the momentum of these larger particles would prevent the catalyst powders from adhering to the surface of the reactor internals. To our surprise, the glass beads were not inert, forming an unidentified species and lowering the catalyst activity. We will try the approach again using a different material.

- Elemental analysis of the spent catalyst from the LPMEOH ${ }^{\mathrm{TM}}$ run using Teflon coatings was performed. The goal was to determine if the Teflon coatings had brought any contaminates into the reactor. Except for greater-than-usual Fe content, no other contaminates were detected. The high Fe content may explain the lower initial catalyst activity and fast catalyst aging in that run. We speculate that the grit-blasting treatment of the reactor internals as part of the Teflon-coating procedures might have generated fresh steel surfaces, which were the source of $\mathrm{Fe}(\mathrm{CO})_{5}$ formation.

- The baffle blade and cooling coil in the \#2 $300 \mathrm{cc}$ autoclave were removed for a LPMEOH ${ }^{\mathrm{TM}}$ life test to minimize the surface area that could contribute to catalyst adhesion. The reactor operated under the kinetic-controlled regime without these two internals. However, the rate of catalyst aging was not improved. A ring of catalyst buildup on the walls of the reactor was observed.

- In order to estimate the activity of the catalyst that adhered to the reactor walls in the above experiment, the buildup was re-dispersed in freshly loaded oil. The activity of this "buildup" catalyst was $14 \%$ of the initial activity of the original catalyst load, indicating that the catalyst adhering to the reactor walls does not, or at least not completely, lose its activity. If we assume that this still-active catalyst on the walls did not contribute to the reaction in the original run due to poor mass transfer in the buildup, then the loss of catalyst to the walls can account for, on average, $0.034 \% / \mathrm{hr}$ catalyst activity loss. This number closely matches the difference in the catalyst-aging rate between lab and LaPorte plant reactors.

- A literature search suggests that adhesion of catalyst to the reactor walls is possibly driven by electrostatic charge. $\zeta$-potential measurements showed that the catalyst particles in spent slurries were negatively charged. These findings may provide the leads to the root cause of the reactor artifact, and eventually to solutions.

- A bench-top experiment using a Plexiglas reactor and spent slurry showed that catalyst buildup in the interface area between slurry and headspace could be the result of low flow momentum or drag in this area. 


\section{LPMEOH ${ }^{T M}$ Kinetics}

- Additional efforts were made to understand the possible source of greater scatter in the Kingsport life data from our new kinetic model. The goal was to better use the new model, which is more robust over a wide range of reaction conditions than our old model, for plant life studies.

- A draft of a DOE topical report entitled "Development of the Kinetic Models for the Liquid Phase Methanol (LPMEOH ${ }^{\mathrm{TM}}$ ) Process" was finished. It covers Air Products' recent work on developing new reaction network and rate models for the $\mathrm{LPMEOH}^{\mathrm{TM}}$ process and the results from LPMEOH ${ }^{\mathrm{TM}}$ experiments with water injection.

- During the process of writing the report, three small errors in the rate models for two side reactions were uncovered and corrected.

\section{Windup Activities for Cooperative Agreement}

- With the approach of the conclusion of the Cooperative Agreement, initial assessment of the equipment in the laboratories and the LaPorte AFDU was made. Dismantlement of Air Products-owned equipment at the Iron Run laboratories was initiated during the reporting period. Work began on a draft version of the Final Report, and the status of the preparations was reviewed at a meeting with DOE in Allentown on 23 May 2002. 